\title{
Estudio Inmunohistoquímico Comparativo del Receptor de Estrógeno en Tejido Endometrial de Ovejas Razas Texel y Araucana
}

\author{
Comparative Inmunohistochemical Study of Estrogen Receptor in \\ Endometrial Tissue from Texel and Araucana Sheeps
}

Adriana Vasconcellos*; Carla Cisternas*** \& Marco Paredes**

VASCONCELlos, A.; CISTERNAS, C. \& PAREDES, M. Estudio inmunohistoquímico comparativo del receptor de estrógeno en tejido endometrial de ovejas razas Texel y Araucana. Int. J. Morphol., 32(3):1120-1124, 2014.

RESUMEN: La asociación de factores genéticos, nutricionales y ambientales afecta directamente la fertilidad de las ovejas sin embargo en condiciones de similitud ambiental, la raza es un factor determinante existiendo razas de alta fertilidad como por ejemplo Texel y Suffolk y otras de fertilidad estándar tales como Romney y Criolla Araucana. La fertilidad es modulada por las hormonas sexuales que actúan mediante la unión a receptores específicos. En ovinos el receptor de estrógeno alfa (ER-a) esta ampliamente distribuido en el sistema reproductivo y es responsable de la modulación de varios mecanismos asociados con la función del sistema reproductivo. Un factor posiblemente relacionado con la diferencia en la fertilidad entre razas de ovinos, es el nivel de expresión diferencial de estos receptores en el sistema reproductivo. En el presente estudio se realizo una comparación cuantitativa de la expresión inmunohistoquímica de ER-a se llevó en el endometrio de ovejas prepúberes de ovejas de alta fertilidad (Texel) y de fertilidad estándar (Araucana), mediante la medición de la densidad óptica integrada de la señal inmunohistoquímica en áreas específicas del endometrio. Los resultados indican una diferencia significativa entre la expresión del ER-a a favor de ovejas de raza Texel en todas las áreas de la raza del endometrio de ovejas prepúberes evaluadas. Esta expresión diferencial sugiere una posible relación entre la intensidad de la expresión de ER-a y la fertilidad en las razas ovinas estudiadas en este trabajo.

PALABRAS CLAVE: Receptor de estrógeno alfa; ER-a; Prolificidad; Texel; Criolla araucana.

\section{INTRODUCCIÓN}

Los mecanismos de control endocrino en la reproducción animal están mediados por hormonas sexuales. Los estrógenos son una de las principales hormonas que modulan el funcionamiento del tracto reproductivo femenino, el comportamiento reproductivo y los caracteres sexuales secundarios (Muramatsu \& Inoue, 2000; Meikle et al., 2001). El efecto hormonal a nivel celular depende de la presencia de receptores específicos en los tejidos blancos. La importancia de éstos radica en la dinámica generada por el complejo hormona-receptor que determinan el estado morfofuncional del tracto genital, dependiendo también de factores como la respuesta celular, su afinidad por los receptores, el estado hormonal, la expresión selectiva en órganos diana, y de distintos factores que afectan la sensibilidad y función de los tejidos (Vasconcellos et al., 2011). En ovinos, animales poliéstricos estaciónales, los estrógenos tienen efecto a nivel del aparato reproductor de la hembra actuando sobre el desarrollo morfofuncional del endometrio (Wiley et al., 1987; Vasconcellos et al., 2010). Una baja expresión del RE-a produciría cambios en la sensibilidad endometrial a las hormonas esteroidales, lo que en estadios de preñez tempranos impediría un desarrollo uterino adecuado, situación que afectaría a la implantación y sobrevida del embrión (Sosa et al., 2004; Abecia et al., 2006). La presencia de estos receptores durante el periodo reproductivo es fundamental, ya que comenzada la actividad ovárica intervienen en los cambios que se producen en el endometrio durante el ciclo estral (Meikle et al., 2004; Vasconcellos et al., 2006).

A diferencia de otros mamíferos, en el endometrio ovino se encuentran receptores de estrógenos fisiológicamente activos desde la etapa prepuberal (Garfolo \& Tasende, 1996; Meikle et al., 1997, 2000, 2001, 2004;

\footnotetext{
* Centro Biotecnológico de la Reproducción, Universidad de La Frontera, Temuco, Chile.

** Laboratorio de Investigación en Biotecnología Animal, Universidad de La Frontera, Temuco, Chile.
} 
Vasconcellos et al., 2009). Sin embargo aun no se comprende el rol funcional de la presencia de estos receptores en hembras prepúberes. Algunas hipótesis, señalan una posible relación entre el nivel de expresión endometrial de este receptor y la prolificidad de la raza (Vasconcellos et al., 2009, 2011, 2012).

La raza Criolla Araucana recientemente caracterizada en su aspecto morfo-estructural y productivo (Bravo, 2010; Sepúlveda et al., 2001), presenta un 9,6 a 20\% de partos dobles alcanzando una prolificidad de $109-120 \%$, considerándola una raza de prolificidad estándar (Sepúlveda $e t$ $a l$.). Por otro lado Los rebaños Texel presentan elevados índices de fertilidad por encima del $95 \%$ de preñez. En condiciones normales de alimentación, teniendo entre 20 a $40 \%$ de gestación de mellizos y prolificidad promedio de 165210\% (Asociación Argentina de Productores de Texel, 2014).

No existen estudios en los cuales se hayan analizado los niveles de expresión endometrial del RE-a entre razas de ovejas con prolificidad desigual. De este modo el propósito de este trabajo fue precisamente evaluar comparativamente el nivel de expresión de los RE-a en ovario de ovejas de prolificidad estándar (Criolla Araucana) y de alta prolificidad (Texel) mediante análisis cuantitativo por inmunohistoquímica y densidad óptica integrada.

\section{MATERIAL Y MÉTODO}

Animales y muestras biológicas. Se utilizaron 6 ovejas prepúberes de 4 meses de edad; 3 de raza Texel y 3 de raza Araucana. Los animales fueron mantenidos en el Campo Experimental Maquehue de la Universidad de La Frontera (Región de La Araucanía), Chile, hasta el sacrificio. En cuanto a la alimentación, las ovejas fueron sometidas a crianza extensiva en base a pradera mixta, con ballica perenne y trébol blanco. El manejo de los animales se realizó de acuerdo con el consentimiento del Comité de Ética de la Facultad de Medicina de La Universidad de La Frontera. Luego del sacrificio con pentobarbital sódico (100 a $200 \mathrm{mg} / \mathrm{Kg}$ ) vía intravenosa (Gnanalingham et al., 2005), se extrajo el útero y se diseccionaron ambos cuernos, los cuales fueron fijados en formalina al $10 \%$ tamponada a $\mathrm{pH}$ 7,0 con buffer de fosfatos por $24 \mathrm{~h}$. Se tomaron cortes transversales de $5 \mathrm{~mm}$ de longitud y se procesaron histológicamente para su inclusión en Paraplast Plus (Mc Cormick scientific, USA). Posteriormente se obtuvieron cortes de $5 \mu \mathrm{m}$ de grosor los que fueron montados en portaobjetos para estudio inmunohistoquímico. Del endometrio de la pared uterina fueron consideradas para el estudio las siguientes áreas: Carunculares e intercarunculares (epitelio de revestimiento, epitelio glandular y estroma), tanto a nivel superficial (cercano al lumen) y profundo (cercano al miometrio).

Análisis Inmunohistoquímico. Los cortes se procesaron desparafinando con xilol y posteriormente rehidratando mediante incubación en batería de concentración decreciente de etanol, con un posterior lavado con tampón fosfato salino 1X (PBS). Luego, se bloqueó la actividad peroxidasa endógena natural, incubando con perhidrol 0,3\% en metanol por $30 \mathrm{~min}$. Se lavó con PBS 3 veces por 5 min y se procedió a incubar los cortes con solución de bloqueo provista por el Kit R.T.U Vectastain Universal Elite ABC Kit, $\mathbf{N}^{\circ}$ Cat. PK-7200 (Vector Laboratories, USA), a temperatura ambiente por 30 minutos. Los cortes se incubaron a continuación con el anticuerpo policlonal anti-REa, $\mathrm{N}^{\circ}$ Cat. Sc7207, lote G1308, (Santa Cruz Biotechnology, USA) diluido 1:500, en solución de bloqueo, durante $12 \mathrm{~h}$ a $37^{\circ} \mathrm{C}$. Posteriormente, los cortes se lavaron con PBS, 3 veces por $5 \mathrm{~min}$. Luego se incubaron con un segundo anticuerpo biotinilado provisto por el kit descrito anteriormente, por $30 \mathrm{~min}$ a temperatura ambiente. Posteriormente, los cortes se lavaron con PBS 3 veces por 5 min y se procedió a incubar con el reactivo Vectastain Elite ABC reagent (provisto por el kit), por $30 \mathrm{~min}$. Finalmente se lavaron 3 veces por 5 min con PBS. La detección cromogénica se realizó incubando en solución diaminobencidina/peroxido de hidrógeno, $0,5 \%$ en PBS, a temperatura ambiente por $10 \mathrm{~min}$. Luego la muestra histológica se lavó con PBS y seguidamente se tiñó para contraste nuclear aplicando hematoxilina 10\% por 1 min y solución de ácido bórico $1 \%$ por $30 \mathrm{~s}$. Seguidamente, se deshidrató en una batería creciente de etanol y se diafanizó con xilol. Finalmente, los cortes se montaron con resina Entellan (Merck, USA).

Análisis de densitometría óptica integrada. La captura de imágenes digitales se efectuó con un microscopio Olympus modelo CX31, acoplado una cámara digital Cannon PC1089. Para el análisis de densitometría óptica integrada (DOI), las imágenes fueron procesadas en formato TIFF a través del programa Image-Pro Plus 6.0®, (Mediacybernetics, USA). Por cada una de las tres muestras uterinas se evaluaron 5 cortes histológicos sumando un total de 15 campos microscópicos del endometrio por cada grupo. Los resultados de la densidad óptica integrada (DOI) se presentaron como el promedio de los datos obtenidos de los 15 campos.

Análisis estadístico. Los resultados fueron expresados como la media más la desviación estándar. Se comparó la media de los grupos por ENDEVA y prueba de F. Se consideró un valor $\mathrm{P}<0,05$ como estadísticamente significativo. Los análisis se realizaron utilizando el programa GraphPad Prism 5.0 para Windows (GraphPad Software Inc, USA). 


\section{RESULTADOS}

La Figura 1, muestra marca inmunoreactiva en distintas áreas del endometrio de oveja de raza Texel, se aprecia claramente expresión inmunohistoquímica de RE-a en áreas estromales (Fig. 1, letra b), epitelio glandular (Fig. 1, letra c) y epitelio de revestimiento (Fig. 1, letra a). El con-

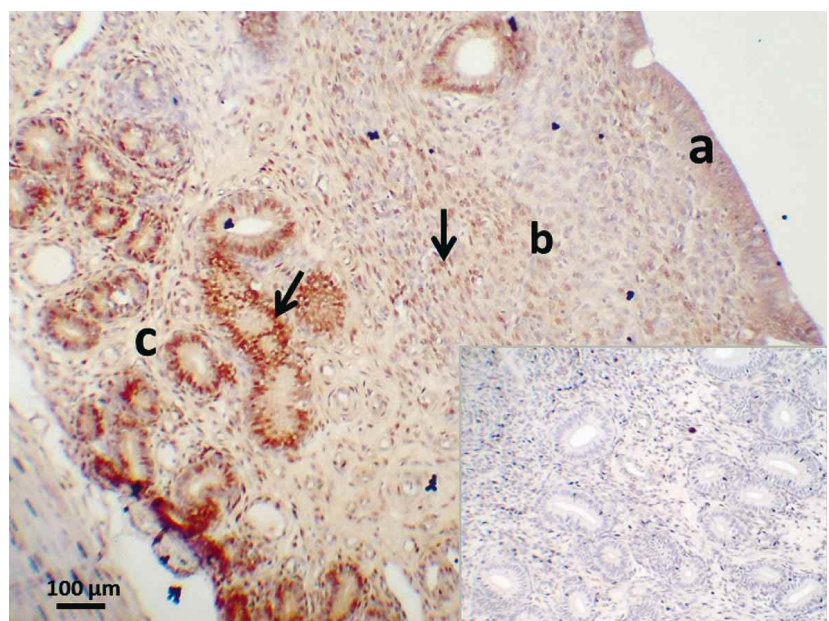

Fig. 1. Expresión inmunohistoquímica del RE-a en endometrio de oveja prepuber de raza Texel. Recuadro inferior: control negativo. a) Epitelio de revestimiento, b) Estroma, c) Epitelio glandular. La flecha indica núcleos de células inmunorreactivas (40x). trol negativo (Fig. 1, recuadro inferior) no muestra marca inmunoreactiva lo cual demuestra la especificidad del anticuerpo utilizado. Cualitativamente, la mayor intensidad del marcaje inmunohistoquímico se aprecia a nivel de la zona glandular basal en ambas razas (Figs. 2A y 2B). A nivel de la zona glandular luminal se distingue mayor intensidad de la marca inmunohistoquímica en endometrio de raza Texel (valores DOI, 0,22 y 0,85) lo que también es corroborado por el análisis de DOI que muestra una diferencia estadísticamente significativa con respecto a la misma zona en raza Araucana (valores DOI, 0,17 y 0,14) (Fig. 2C). En la Figura 3, se aprecia claramente una intensa inmunorreacción en núcleos de células epiteliales glandulares en ovejas Texel que difiere significativamente de Araucana, según el análisis DOI con valores de 0,27 y 0,19 respectivamente (Figs. 3A, 3B y 3C). El mismo tipo de análisis, muestra que en núcleos de células estromales la intensidad de la inmunorreacción es significativamente mayor en raza Texel con valores de DOI de 0,29 y de 0,15 en estroma de Araucana. (Figs. 4A, 4B y 4C). Además, la marca inmunoreactiva en los núcleos celulares del epitelio de revestimiento es significativamente mayor en ovinos Texel con valores de DOI de 0,23 contra 0,16 medido en epitelio luminar de Araucana (Figs. 5A, 5B y 5C).
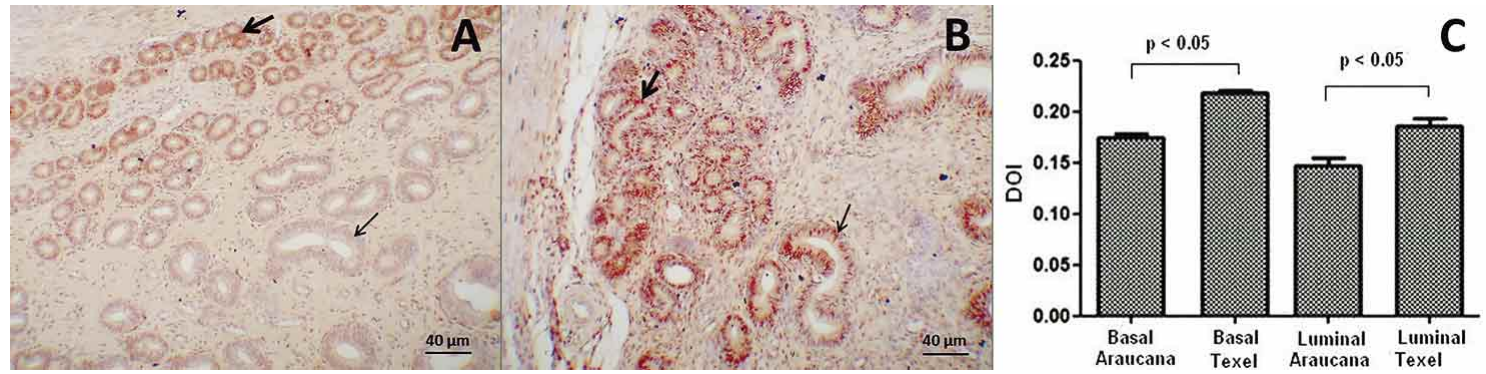

Fig. 2. Expresión inmunohistoquímica del RE- a en endometrio de ovejas prépuberes de raza Araucana (A) y Texel (B). Se aprecia una marcada inmunoreacción en glándulas de zona basal (flechas gruesas), que disminuye intensidad hacia glándulas superficiales (flechas finas) en ambas razas (400x). (C) Análisis por Densitometría Óptica Integrada (DOI) de las zonas destacadas en la fotografía A y B. El análisis DOI se realizó con 15 campos ópticos por cada grupo de 3 ovejas $(\mathrm{p}<0,05)$.
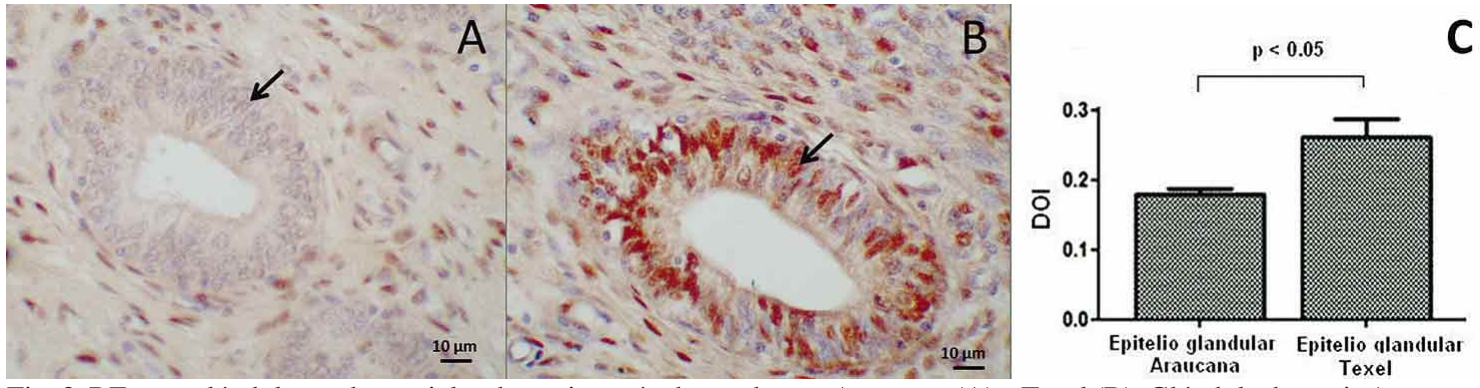

Fig. 3. RE-a en glándulas endometriales de ovejas prépuberes de razaAraucana (A) y Texel (B). Glándula de oveja Araucana con células levemente inmunoreactivas. Glándula de oveja Texel con células intensamente inmunoreactivas (1000x). (C) Análisis de densitometría óptica Integrada de las zonas destacadas en la fotografía A y B. El análisis DOI se realizó con 15 campos ópticos por cada grupo de 3 ovejas $(\mathrm{p}<0,05)$. 

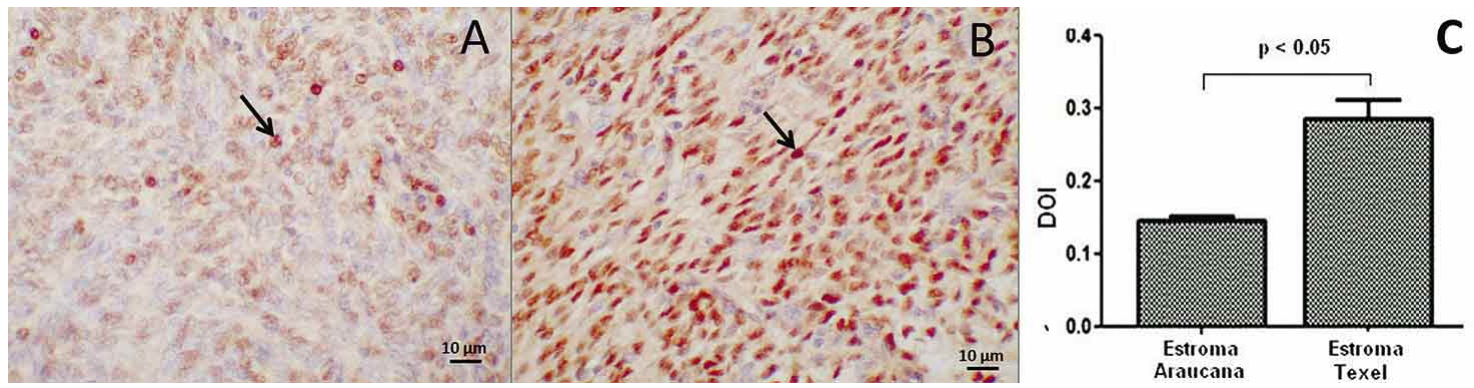

Fig. 4. RE-a en endometrio de ovejas prepúberes de raza Araucana (A) y Texel (B). Células estromales de oveja de raza Texel intensamente inmunoreactivas y en (B) células estromales de oveja raza Araucana levemente inmunoreactivas (1000x). (C) Análisis de Densitometría Óptica Integrada de las zonas destacadas en la fotografía A y B. El análisis DOI se realizó con 15 campos ópticos por cada grupo de 3 ovejas $(\mathrm{p}<0,05)$.
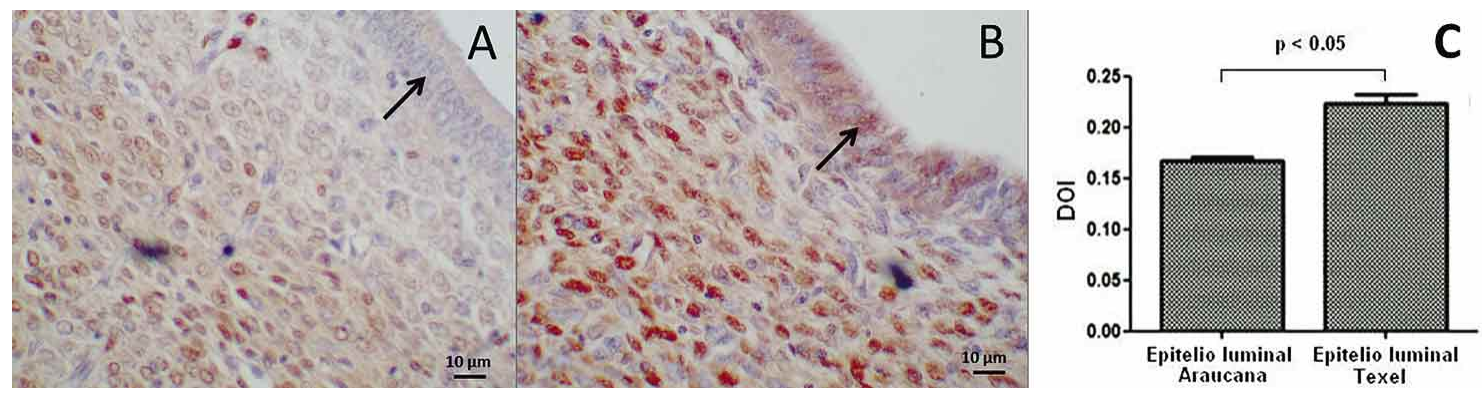

Fig. 5. RE-a en tejido epitelial de ovejas prépuberes de raza Araucana (A) y Texel (B). Epitelio de revestimiento en endometrio de oveja Araucana levemente inmunoreactivo y epitelio de revestimiento de oveja Texel intensamente inmunoreactivo (1000x). (C) Análisis de Densitometría Óptica Integrada de las zonas destacadas en la fotografía A y B. El análisis DOI se realizó con 15 campos ópticos por cada grupo de 3 ovejas $(\mathrm{p}<0,05)$.

\section{DISCUSIÓN}

De acuerdo al análisis inmunohistoquímico, los animales prepuberes de las razas Texel y Araucana expresan el RE-a, a nivel endometrial. Sin embargo, los datos muestran una clara diferencia en el nivel de expresión de este recepto entre estas razas, siendo significativamente mayor en Texel. En un estudio reciente, Vasconcellos et al. (2011) señalan que la expresión transcripcional del RE-a en el sistema reproductivo de ovejas de raza Texel presenta una distribución histológica similar a lo visto en otras razas, destacándose un mayor nivel de expresión transcripcional del RE-a en endometrio, lo cual es consistente con los datos de expresión de la proteína receptora evaluada por inmunohistoquímica en este trabajo, sin embargo estos autores no realizaron estudios comparativos entre razas.

La expresión de receptores de RE-a en animales adultos está asociada a mecanismos de diferenciación y proliferación celular que hacen posible la funcionalidad reproductiva, sin embargo, no está claro aún el rol funcional de la expresión de estos receptores en hembras ovinas prepúberes (Meikle et al., 2004), más aún considerando que otros mamíferos no expresan receptores durante la etapa prepuberal (Vasconcellos et al., 2006). Un posible efecto o función asociado a la expresión de RE-a en endometrio de prepúberes podría estar relacionado con la prolificidad, ya que algunos trabajos asocian la baja expresión del RE-a con cambios en la sensibilidad endometrial a las hormonas esteroidales, lo que impediría un desarrollo uterino adecuado y una baja prolificidad (Lozano et al., 1997; Sosa et al.; Abecia et al.; Vasconcellos et al., 2009). De este modo, una oveja prépuber con mayores niveles de expresión de receptores podría tener una respuesta más eficiente frente al impacto hormonal durante sus ciclos reproductivos, y esto podría traducirse en un mayor nivel de prolificidad.

Los resultados de este trabajo permiten concluir que la expresión del RE-a presenta una distribución amplia a nivel celular en el tejido endometrial, pero con diferencias importantes en cuanto a la intensidad en las distintas áreas del endometrio. También se concluye que existen diferencias en la expresión del RE-a en endometrio de ovejas prepúberes entre ambas razas, siendo significativamente mayor en Texel.

Estos resultados sugieren que la diferencia de expresión de este receptor en ovejas prepúberes de razas Texel y Araucana, eventualmente podrían estar relacionada con el nivel de prolificidad que presentan estos ovinos. 
AGRADECIMIENTOS A la Dirección de Investigación de la Universidad de La Frontera, Temuco, Chile, por el apoyo económico entregado, mediante el proyecto DIUFRO DI120027. También, se agradece al Laboratorio de Investigación en Biotecnología Animal (LINBA) de la Universidad de La Frontera por el apoyo en el uso de su infraestructura y utilización de reactivos para la realización de este trabajo.

VASCONCELlOS, A.; CISTERNAS, C. \& PARECES, M. Comparative Inmunohistochemical study of estrogen receptor in endometrial tissue from Texel and Araucana sheeps. Int. J. Morphol., 32(3):1120-1124, 2014.

SUMMARY: In breeding sheep high fertility rate is an important consideration factor. The association of genetic, nutritional and environmental conditions directly affects the fertility of ewes. There are high fertility sheep breeds (Texel, Suffolk) and other standard fertility breeds as (Romney, Criolla Araucana). Animal reproduction is modulated by sex hormones that act by binding to specific receptors. In sheep, alpha (ER-a) estrogen receptor is widely distributed in the reproductive system, modulating several mechanisms associated with reproductive system function. One factor possibly related to the difference in fertility between sheep breeds, is the differential expression level of these receptors in the reproductive system. In the present study a quantitative comparison of the immunohistochemical expression of ER-a was carried out in prepubertal sheep endometrium in high fertility (Texel) breed versus standard fertility (Araucana) breed, by measuring the integrated optical density in specific areas of the endometrium. Results indicate a significant difference between ER-a expression in endometrium off Texel breed ewes and Araucana breed ewes, and registered higher levels in all areas of evaluated Texel breed prepubertal ewes. This differential expression suggests a possible link between ER-a expression intensity and fertility in the breeds studied in this work.

KEY WORDS: Alpha estrogen receptor; ER-a; prolificity; Texel; Criolla araucana.

\section{REFERENCIAS BIBLIOGRÁFICAS}

Abecia, J. A.; Sosa, C.; Forcada, F. \& Meikle, A. The effect of undernutrition on the establishment of pregnancy in the ewe. Reprod. Nutr. Dev., 46(4):367-78, 2006.

Asociación Argentina de Productores de Texel (A. A. P. T.). 2014. Disponible en: http://www.texel.org.ar/

Bravo, S.; Fabres, M.; Schnettler, B. \& Sepúlveda, N. Corporal composition and characteristics of carcass of araucano creole lambs. Int. J. Morphol., 28(4):1107-11, 2010

Gnanalingham, M. G.; Mostyn, A.; Symonds, M. E. \& Stephenson, T. Ontogeny and nutritional programming of adiposity in sheep: potential role of glucocorticoid action and uncoupling protein-2. Am. J. Physiol. Regul. Integr. Comp. Physiol., 289(5):R1407-15, 2005.

Garófalo, E. G. \& Tasende, C. Uterine estrogen and progesterone receptors in prepuberal ewe distribution in myometrium, endometrium, and caruncles. Vet. Res., 27(2):177-3, 1996.

Lozano, J. M.; Abecia, J. A.; Forcada, F.; Zarazaga, L. \& Alfaro, B. Effect of undernutrition on the distribution of progesterone in the uterus of ewes during the luteal phase of the estrous cycle. Theriogenology, 49(3):53946, 1998 .
Meikle, A.; Tasende, C.; Rodríguez, M. \& Garófalo, E. G. Effects of estradiol and progesterone on the reproductive tract and on uterine sex steroid receptors in female lambs. Theriogenology, 48(7):1105-13, 1997.

Meikle, A.; Forsberg, M.; Sahlin, L.; Masironi, B.; Tasende, C.; Rodríguez-Piñón, M. \& Garófalo, E. G. A biphasic action of estradiol on estrogen and progesterone receptor expression in the lamb uterus. Reprod. Nutr. Dev., 40(3):283-93, 2000.

Meikle, A.; Garófalo, E. G.; Rodríguez-Piñón, M.; Tasende, C. \& Sahlin, L. Regulation by gonadal steroids of estrogen and progesterone receptors along the reproductive tract in female lambs. Acta Vet. Scand., 42(1):161-9, 2001.

Meikle, A.; Tasende, C.; Sosa, C. \& Garófalo, E. G. The role of sex steroid receptors in sheep female reproductive physiology. Reprod. Fertil. Dev., 16(4):385-94, 2004.

Muramatsu, M. \& Inoue, S. Estrogen receptors: how do they control reproductive and nonreproductive functions? Biochem. Biophys. Res. Commun., 270(1):110, 2000.

Sepúlveda, N.; Neculmán, R.; Herrera, M. \& Rodero, E. Parámetros de fertilidad natural en ovejas de la agrupación araucana. En: Sierra Alfranca, I.; Alcalde Aldea, Ma. J.; González Redondo, P.; Fernández Cabanás, V. \& Morales Ruiz, F. A. (Eds.). XXVI Jornadas Científicas y V Internacionales de la Sociedad Española de Ovinotecnia y Caprinotecnia. Sevilla, A. G. Novograt S. A., 2001. pp.962-6.

Sosa, C.; Lozano, J. M.; Viñoles, C.; Acuña, S.; Abecia, J. A.; Forcada, F.; Forsberg, M. \& Meikle, A. Effect of plane of nutrition on endometrial sex steroid receptor expression in ewes. Anim. Reprod. Sci., 84(3-4):337-48, 2004.

Vasconcellos, C. A.; Sepúlveda, B. N. \& Pacheco, C. C. Presence of estrogen and progesterone receptors and cbg in the female tract of sheep and dogs. Comparative immunochemistry study. Int. J. Morphol., 24(3):457-62, 2006.

Vasconcellos, C. A.; Paredes H. M.; Barrientos, V. E.; Olmazábal, S. Y.; Núñez, R. D.; Navarrete, V. J. \& Molina, E. B. Analysis of the expression of estrogen receptors in the endometrium of ewes fed with normal and supplementary diet. Int. J. Morphol., 27(4):1093-8, 2009.

Vasconcellos, C. A.; Paredes, H. M.; Núñez, R. D.; Barrientos, V. E.; Olmazábal, S. Y.; Núñez, R. D. \& Navarrete, V. J. Study of the expression of progesterone receptors in the endometrium of ewes with normal and supplementary diet. Int. J. Morphol., 28(2):575-81, 2010.

Vasconcellos, C. A.; Paredes, H. M.; Hernández, V. C.; Muñoz, S. A. \& Navarrete, V. J. Expression of Estrogen and Progesterone Receptors in the Genital Tract of Texel Ewes. Int. J. Morphol., 29(4):1268-73, 2011.

Vasconcellos, C. A. \& Paredes, H. M. Immunohistochemical Detection of Estrogen Receptor in the Endometriumof Sheep High Prolificacy and Standard Prolificacy. Int. J. Morphol., 30(3):1090-3, 2012.

Wiley, A. A.; Bartol, F. F. \& Barron, D. H. Histogenesis of the ovine uterus. J. Anim. Sci., 64(4):1262-9, 1987.

\section{Dirección para Correspondencia: \\ Dr. Marco Paredes}

Laboratorio de Investigación en Biotecnología Animal

Universidad de La Frontera

Temuco -CHILE

Recibido: 10-07-2014

Aceptado:11-08-2014

Email: marco.paredes@ufrontera.cl 